\title{
The effectiveness of silver-releasing dressings in the management of non-healing chronic wounds: a meta-analysis
}

\author{
Shu-Fen Lo, Chee-Jen Chang, Wen-Yu Hu, Mark Hayter and Yu-Ting Chang
}

Aim. The purpose of this study was to examine the efficacy of silver-releasing dressings in the management of non-healing chronic wounds.

Background. Non-healing chronic wounds often have a negative physical impact on patients and place a financial burden on healthcare systems. Silver dressings are wound products designed to control infection and provide a wound environment conducive to healing. However, validation of the clinical efficacy of these dressings is lacking.

Design. Systematic review and meta-analysis.

Methods. A systematic search of the major electronic databases PubMed, CINAHL, Cochrane, MEDLINE, British Nursing Index, EBSCO, OCLC and Proquest between 1950-June 2007 was conducted. Hand searches of selected periodicals, textbooks and checking reference lists and contacting experts was also performed.

Results. Eight studies were selected from a potentially relevant 1957 references screened. Analysis incorporated data from 1399 participants in the eight randomised control trials. We found that silver dressings significantly improved wound healing $\left(\mathrm{CI}_{95}\right.$ : $0 \cdot 16-0 \cdot 39, p<0 \cdot 001)$, reduced odour $\left(\mathrm{CI}_{95}: 0 \cdot 24-0 \cdot 52, p<0 \cdot 001\right)$ and pain-related symptoms $\left(\mathrm{CI}_{95}: 0 \cdot 18-0 \cdot 47, p<0 \cdot 001\right)$, decreased wound exudates $\left(\mathrm{CI}_{95}: 0 \cdot 17-0 \cdot 44, p<0 \cdot 001\right)$ and had a prolonged dressing wear time $\left(\mathrm{CI}_{95}: 0 \cdot 19-0 \cdot 48, p=0 \cdot 028\right)$ when compared with alternative wound management approaches. An analysis of sensitivity in these studies by subgroup analysis generally supported these associations. Furthermore, studies indicated an improvement in quality of life $\left(\mathrm{CI}_{95}\right.$ : $0 \cdot 04-$ $0 \cdot 33, p=0 \cdot 013$ ) using silver dressings in wound management with no associated severe adverse events.

Conclusion. This meta-analysis confirms the effectiveness of silver dressings in wound healing and improving patients' quality of life. However, it also highlights the need for additional well-designed randomised controlled trials to evaluate the effectiveness of silver-related dressings further.

Relevance to clinical practice. The results of this study provide objective data on the effectiveness of silver-related dressing when applied to non-healing chronic wounds.

Key words: clinical effectiveness, meta-analysis, nurses, nursing, review, wound care

Accepted for publication: 11 June 2008

Authors: Shu-Fen Lo, MSc, RN, CWCN, Assistant Professor,
Department of Nursing, Tzu Chi College of Technology and
Doctoral Program Student, School and Graduate Institute of
Nursing, National Taiwan University, Taipei, Taiwan; Chee-Jen
Chang, PhD, Professor, Graduate Institute of Basic Medical
Science, Chang Gung University and Resource Center for Clinical
Research, Chang Gung Memorial Hospital, Taoyuan, Taiwan;
Wen-Yu Hu, PhD, RN, Associate Professor, School of Nursing
Science, College of Medicine and Hospital, National Taiwan
University, Taipei, Taiwan; Mark Hayter, BA(Hons), MSc, PhD,
RN, Senior Lecturer in Nursing, Centre for Health and Social Care
Studies and Service Development, School of Nursing and Midwifery, University of Sheffield, Sheffield, UK; Yu-Ting Chang, MSc, RN, Lecturer, Department of Nursing, Tzu Chi College of Technology and Doctoral Program Student, School and Graduate Institute of Nursing, National Taiwan University, Taipei, Taiwan

Correspondence: Chee-Jen Chang, Professor, Graduate Institute of Clinical Medical Science, Chang Gung University, 259 Wen-Hwa 1st Road, Kwei-Shan, Tao-Yuan, Taiwan, 333, R.O.C. Telephone: 3863 218800 ext. 3573.

E-mail: cjchang@mail.cgu.edu.tw 


\section{Introduction}

Non-healing chronic wounds are a serious health issue: they cause great pain and suffering to patients impacting on their quality of life and place a significant financial burden on health systems.

A recent innovative concept in chronic wound care is represented by the 'wound bed preparation' model proposed by Sibbald et al. (2001) who identifies four main strategies to good wound bed preparation; specifically, tissue management, infection and inflammation control, moisture balance and edge of wound care (Sibbald et al. 2001, Moffatt 2004, Fletcher 2005). When the wound bio-burden exceeds a hostmanageable level, a wound may become infected. Chronic infection is clearly detrimental to wound healing (Tomaselli 2006). Non-healing chronic wounds, e.g. pressure ulcer, venous ulcer, arterial ulcer and diabetic ulceration, are usually contaminated with several species and the progression to local infection occurs in stages, often leading to critical colonisation (Ayello \& Cuddigan 2004, Giulio \& Barrett 2005). When this occurs and host response is reduced, the normal wound healing process is interrupted because of a prolonged inflammatory response, molecular and cellular abnormalities in the wound bed and granulation tissue breakdown resulting in a non-healing and deteriorating wound (Giulio \& Barrett 2005, Gray et al. 2006). Appropriate management of infected and critically colonised wounds is essential to encourage wound healing progression (Bowler 2003). Treatment of infected wounds should focus on the removal of dead or necrotic tissues and the management of wound exudates (Schultz et al. 2003, Ayello \& Cuddigan 2004). Unfortunately, not only there are difficulties in diagnosing critical colonisation or infection, but traditional topical antimicrobials can be toxic to granulation tissues or increase the chance of resistant organisms. It is possible, however, to reduce the wound bio-burden and avoid systemic infection by silver-releasing wound dressings (Gray et al. 2006, White \& Cutting 2006).

Silver, in its common ionic (active) form $\left(\mathrm{Ag}^{+}\right)$, is particularly attractive as an antibacterial agent because it can be readily incorporated into dressing materials. When the materials contact an aqueous environment, the silver complex contained in them is dissociated (Ovington 2004, White \& Cutting 2006). The mechanism of action for $\mathrm{Ag}^{+}$is that it binds to bacterial cell DNA and enzymes and proteins in the cell wall. Once the silver cation attaches to these sites, it alters their structure, resulting in structural and functional changes in the bacterial cell (Ovington 2004). It is suggested by numerous authors that silver dressings should be used when critical colonisation within a wound occurs (Ovington 2004, White \& Cutting
2006). However, the evidence base for this assertion is not particularly strong. If nurses are to provide evidence-based care to their patients a clear, evidence-based, body of knowledge should underpin their practice. In wound care, this means continually reviewing the evidence related to wound management (Leandro 2005, Melnyk \& Fineout-Overholt 2005). This study conducts a meta-analysis of the current evidence base for the efficacy of silver dressings in the treatment of chronically infected wounds. Meta-analysis studies contribute to many aspects of clinical research, not only by enabling an increased statistical power of comparison but also in obtaining clear and reliable results that can be used as a basis for clinical guidelines (Leandro 2005). To date, two meta-analyses have included studies of silver-based dressings and topical agents on leg ulcers (Chambers et al. 2007, Vermeulen et al. 2007). However, information on economic evaluation, duration of dressing wear time and the frequency of dressing change was not specified enough for clinical application. Furthermore, this analysis also sought to analyse the evidence of patient preference and symptom control.

\section{Aim of the study}

This study's purpose was to examine the efficacy and safety of silver-releasing dressings in the management of nonhealing chronic wounds by conducting a meta-analysis of randomised control trials (RCT). Therefore, the research questions addressed in the current meta-analysis were:

- What are the mean effect sizes of silver-releasing dressing as a whole?

- What is the magnitude efficacy and safety of silver-releasing dressings?

\section{Methodology}

\section{Search strategy for identification of studies}

The search for eligible studies was comprehensive and involved multiple strategies. Relevant studies were identified by searching the electronic searches of the core bibliographic databases: PubMed, CINAHL via Ovid online, Cochrane Database, MEDLINE via Ovid online, EBSCO host, Proquest, British Nursing Index and OCLC. The search terms used to locate relevant studies are summarised in Table 1 . Moreover, we also carried out hand searching of selected periodicals, reviewed reference lists of published papers, searched wound management websites and contacted wound dressing manufacturers. A search for unpublished literature was conducted through dissertation and conference abstracts. The time parameters of the search were from 1950s-June 
Table 1 Search strategy for review

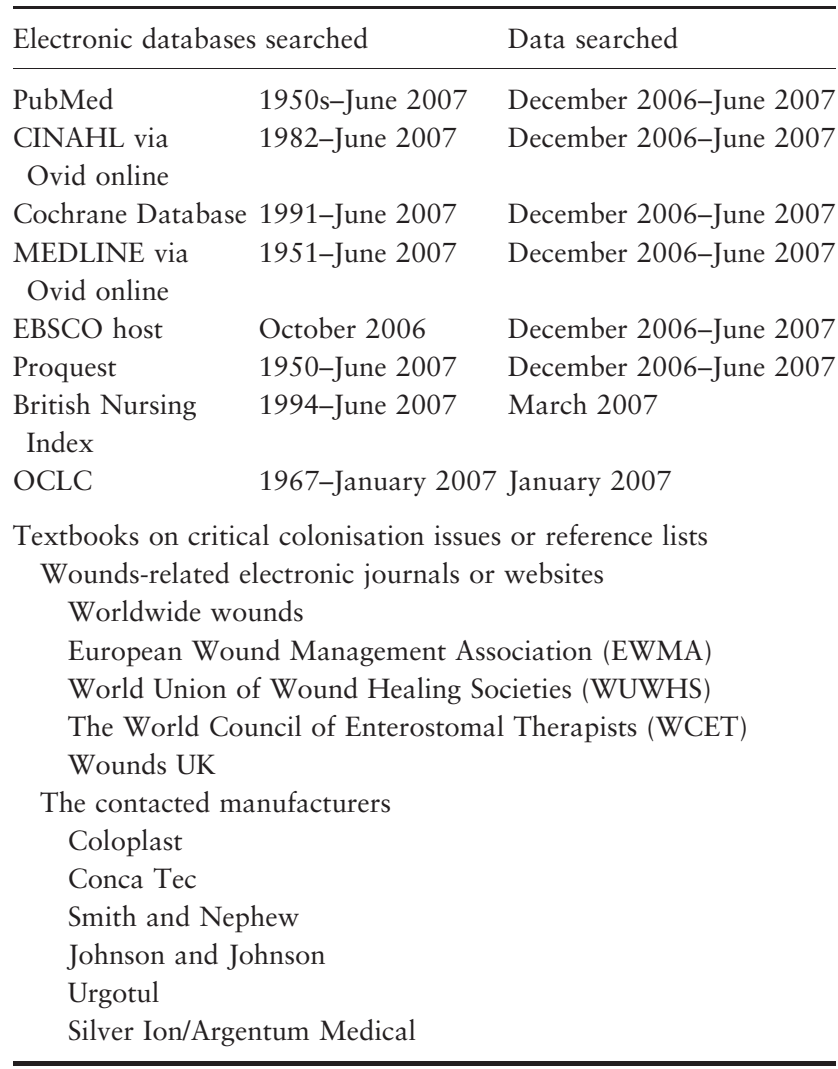

\begin{tabular}{ll}
\hline Search terms used & $\begin{array}{l}\text { Potentially } \\
\text { relevant hits }\end{array}$ \\
\hline \#1 infection $(\mathrm{MeSH})$ or & $(1,10,752)$ \\
\#2 sepsis (MeSH) or & $(9167)$ \\
$\# 3$ colonised or & $(149)$ \\
$\# 4$ colonisation or & $(3201)$ \\
$\# 5$ antimicrobial or & $(9894)$ \\
$\# 6$ silver $(\mathrm{MeSH})$ or & $(2702)$ \\
$\# 7$ Ag or & $(908)$ \\
$\# 8$ ionic silver or & $(1)$ \\
$\# 9$ wounds $(\mathrm{MeSH})$ or & $(6671)$ \\
$\# 10$ diabetic ulcers $(\mathrm{MeSH})$ or & $(142)$ \\
$\# 11$ venous ulcer $(\mathrm{MeSH})$ or & $(286)$ \\
$\# 12$ pressure ulcer $(\mathrm{MeSH})$ or & $(609)$ \\
$\# 13$ \#1 or \# 2 or \#3 or \#4 or \#5 & $(1,32,162)$ \\
$\# 14$ \#6 $\# 7$ or \#8 & $(3600)$ \\
$\# 15$ or \#10 or \#11 or \#12 & $(7696)$ \\
$\# 16$ \#13 and \#14 and \#15 & $(1957)$ \\
\hline
\end{tabular}

2007. The literature search was carried out on 30 June 2007 and papers were included in the review if retrieved by 5 July 2007 (Table 1).

\section{Selection criteria}

Screening of relevant studies for inclusion was conducted independently by S-FL and Y-TC Chang who used titles, publication years and abstracts. The criteria for considering studies for the review were as follows. Studies were assessed for inclusion based on inclusion criteria determined a priori (Fig. 1). Studies excluded after full paper review are presented in Table 2.

\section{Type of studies}

We performed a meta-analysis of primary studies, which concerned the effectiveness of interventions applied to management of non-healing chronic wounds. Owing to language and resource constraints, studies included were limited to published or unpublished papers in English or Chinese. RCT studies were included (single-group pre- and postcontrolled trials or experimental studies were excluded).

Type of participants

Study participants all had wounds that exhibited delayed healing or had wounds that were clinically diagnosed with critical colonisation or infection (acute wounds such as burns were excluded).

\section{Type of intervention}

To be included, studies should focus on silver dressing compared with non-silver dressings or silver dressing compared with traditional wound management, such as gauze.

\section{Type of outcome measurement}

Based on the protocol for this review the reported outcomes were classified as physical, psychological or economic.

\section{Assessment of study quality}

In this review, the title, abstract and key words of each identified record were screened for relevancy (step 1 screening) by the primary reviewers. Full-text articles were obtained for all remaining records. Non-English articles were obtained and translated as required. The same two reviewers independently assessed each full-text article. The quality and strength of the studies were evaluated using the CONSORT statement and the checklist developed by Melnyk and Fineout-Overholt (2005) was used to critically appraise RCT. A total of 15 study elements were critically appraised to determine a study quality score. The highest possible study quality score was 30 ; each item had a possible score of $0-2$ (score of $0=$ not done; 1 for unclear, 2 for done), with possible scores ranging from 0-30. Papers with a quality score over $60 \%(>18)$ of the total possible score were included in this analysis (step 2 screening; Table 3). Inter-rater agreement was calculated at each screening step with the use of Cohen's kappa statistic. 
Figure 1 Summary of study selection and exclusion.
Search done July 2007

Search database $n=9$

Wounds related electronic journal $n=5$

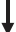

Potentially relevant citations identified 1957 hits (including duplicates)

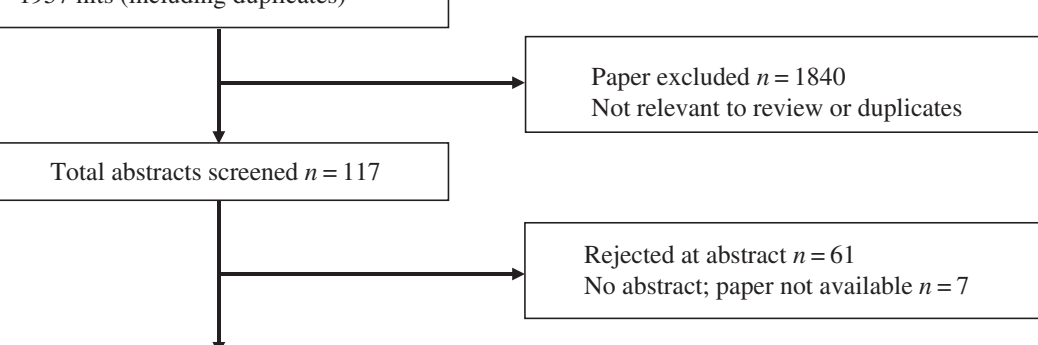

Total full papers screened $n=49$

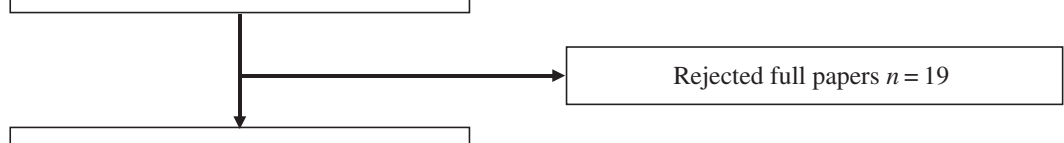

Total papers preliminary inclusion $n=30$

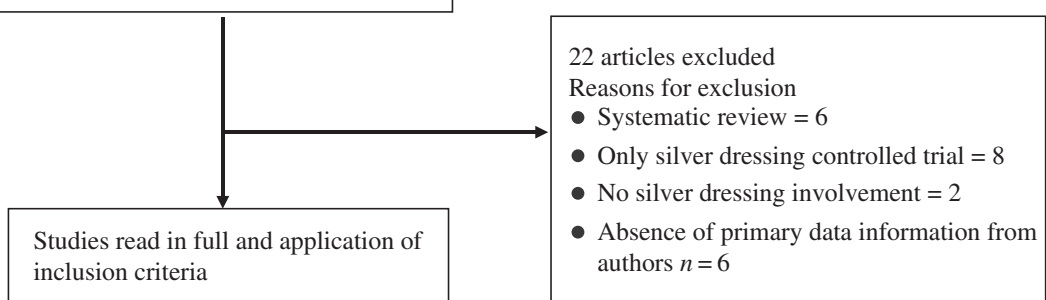

Included studies

$n=8$ randomised controlled trials

Table 2 Excluded studies

\begin{tabular}{|c|c|}
\hline Study & Reason \\
\hline Chambers et al. (2007) & Systematic review and meta-analysis in leg ulcers \\
\hline Bergin and Wraight (2006) & Systematic review in diabetic foot ulcer \\
\hline Sibbald et al. (2005) & Lacking in rigour \\
\hline O’Meara et al. (2001) & Lacking in rigour \\
\hline Bolton (2006) & Lacking in rigour \\
\hline Rayman et al. (2005) & Non-comparative study \\
\hline Lazareth et al. (2007) & Non-comparative study \\
\hline Sibbald et al. (2001) & Non-comparative study \\
\hline Schuman et al. (2007) & Non-comparative study \\
\hline Karlsmark et al. (2003) & Non-comparative study \\
\hline Ziegler et al. (2006) & Non-comparative study \\
\hline Vanscheidt et al. (2003) & Non-comparative study \\
\hline Joergensen et al. (2007) & Non-comparative study \\
\hline Verdu et al. (2007) & Non-comparative study \\
\hline Rucigaj (2007) & Non-comparative study \\
\hline Sigal-Grinberg et al. (2007) & No useable data was reported \\
\hline Verdu Soriano et al. (2004) & Definition of outcomes unclear. No further data could be obtained \\
\hline Rogers and Alvarez (2004) & Definition of outcomes unclear. No further data could be obtained \\
\hline Serra et al. (2005) & Definition of outcomes unclear. No further data could be obtained \\
\hline
\end{tabular}


S-F Lo et al.

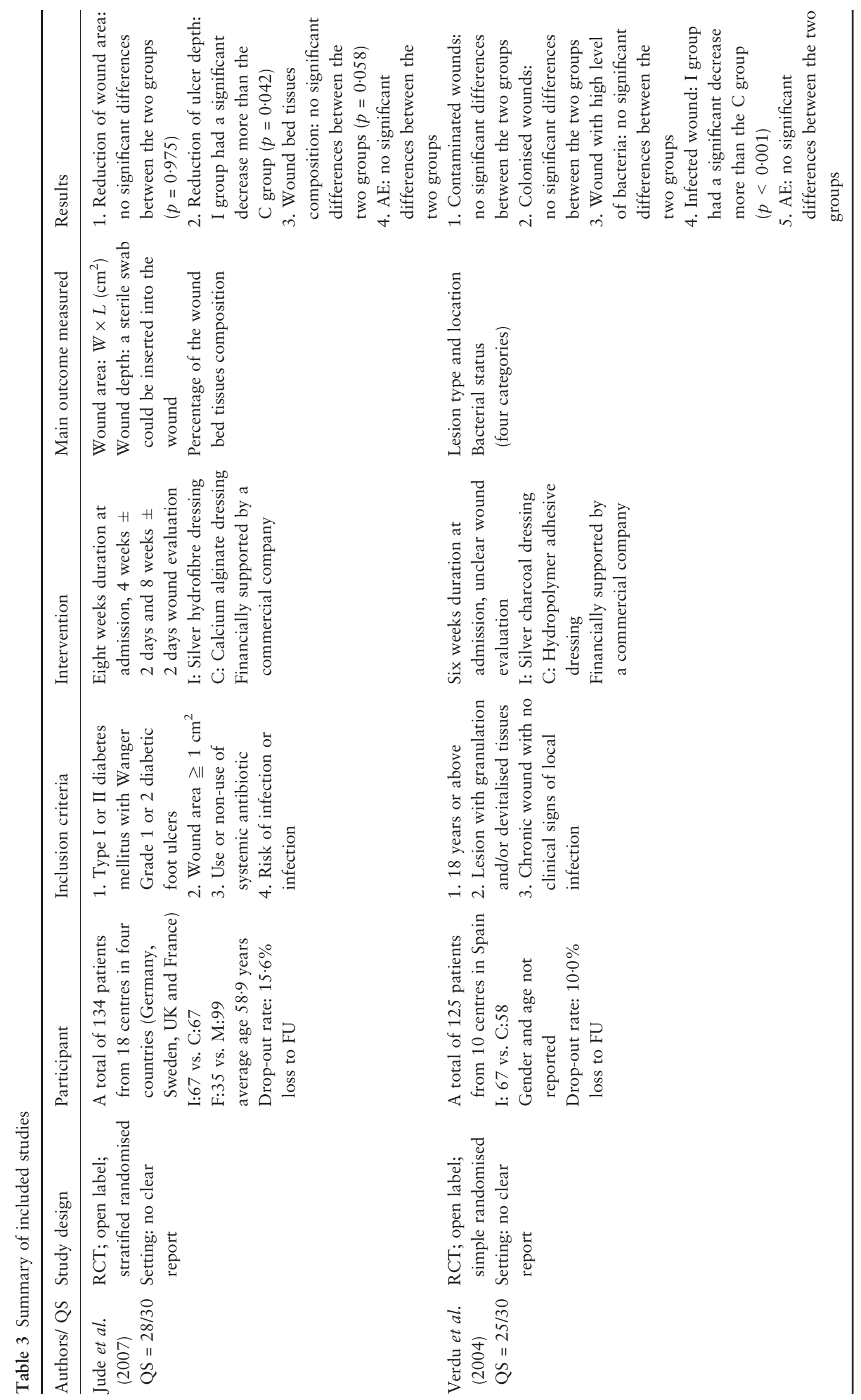




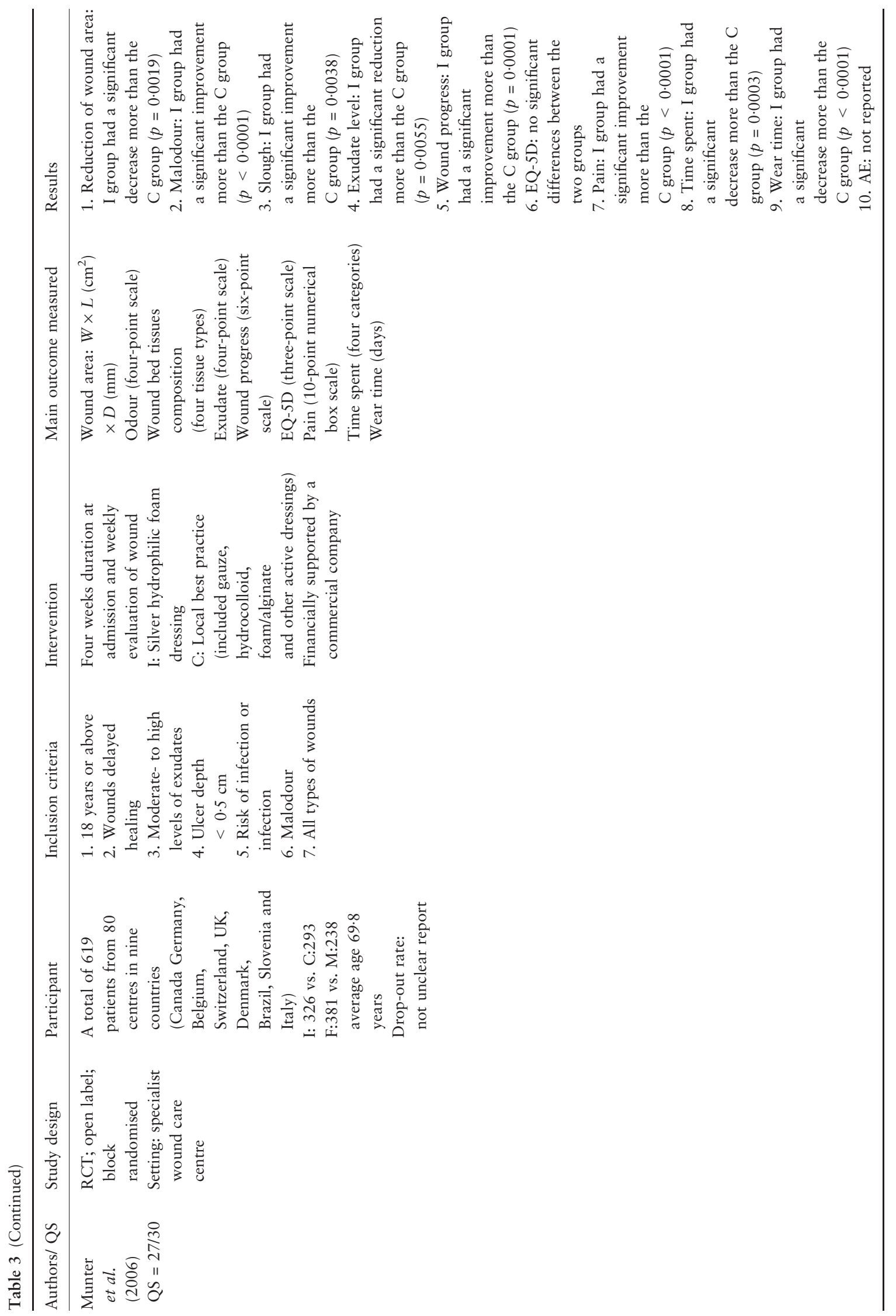




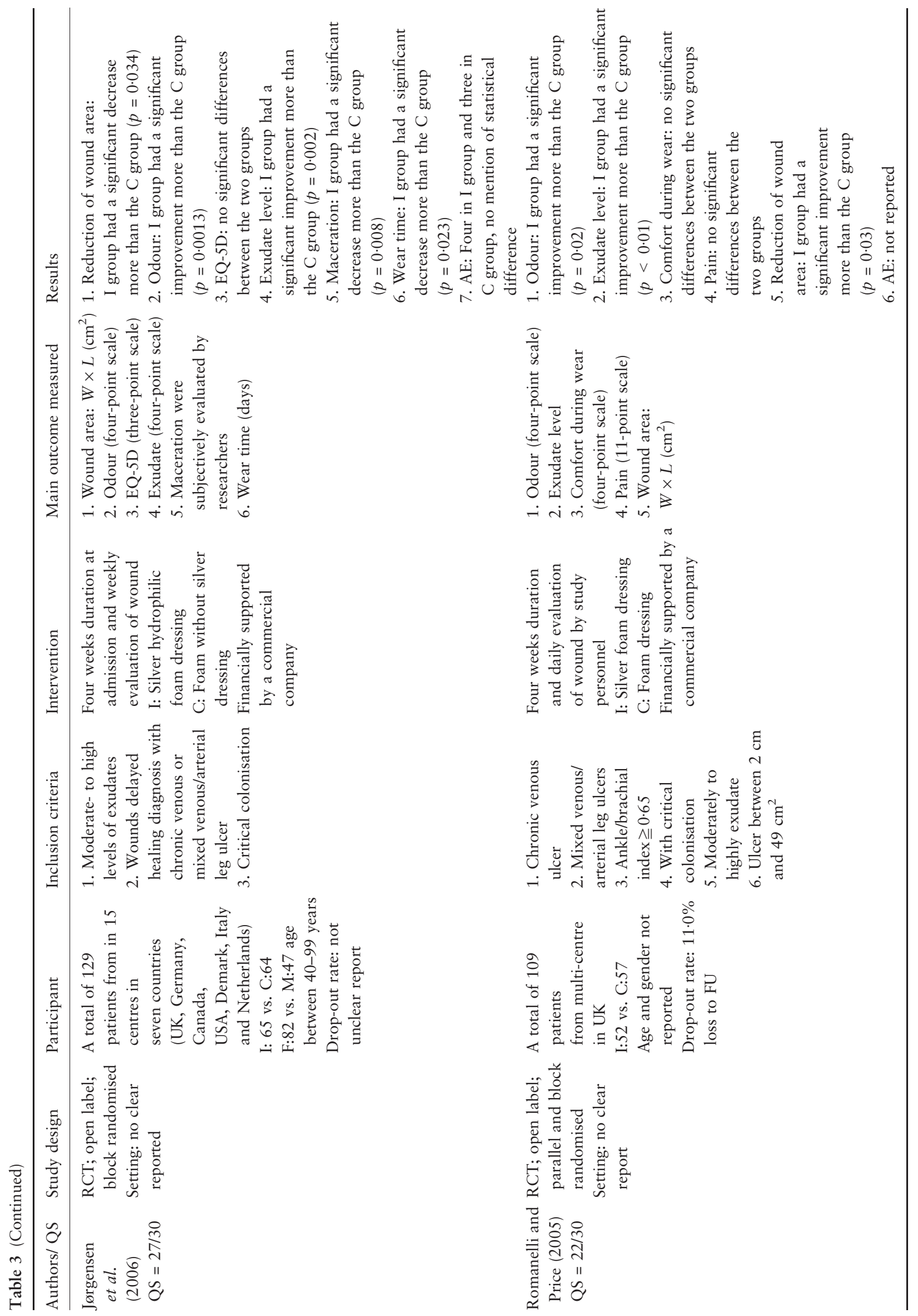




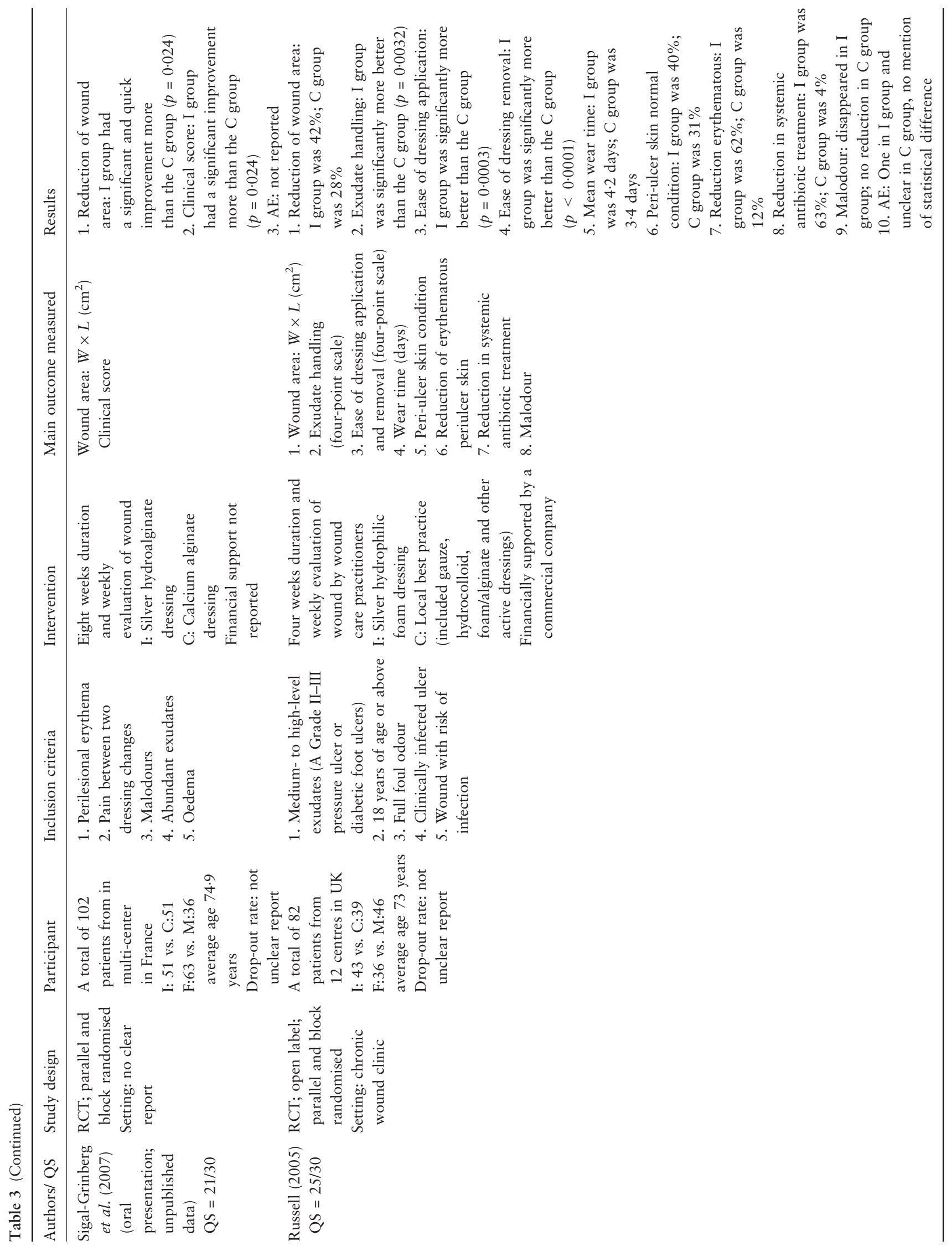




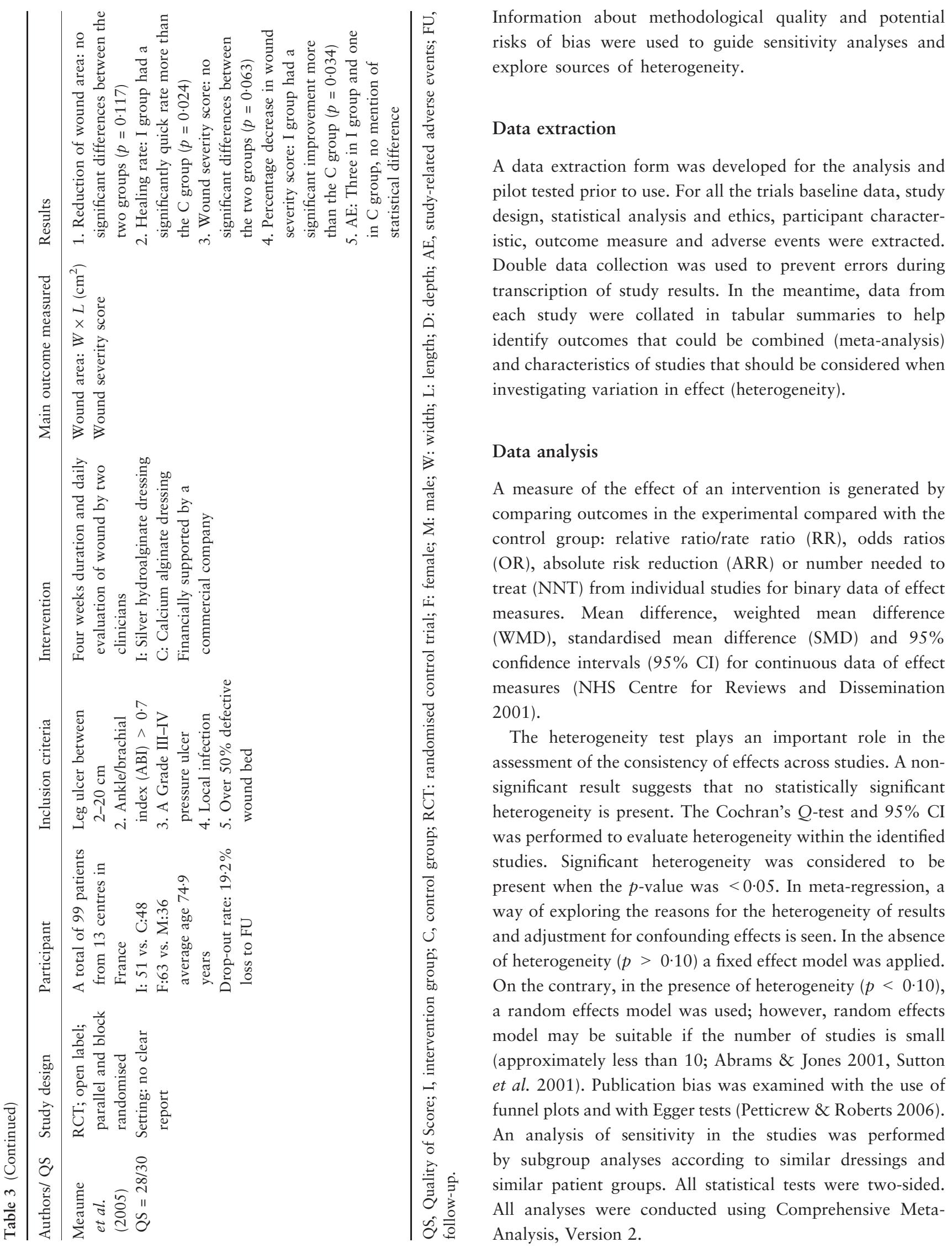




\section{Results}

\section{Search results}

Figure 1 shows the steps and criteria for search strategy and the number of trials evaluated at each stage of the systematic review. Primary searched studies resulted in potentially relevant citations and identified 1957 hits (step 1). The agreement between the two primary reviewers at this step of screening was substantial (estimated kappa $=0.79$ ). Of these, 30 studies were reviewed and eight RCT were included. Twenty-two were excluded from the meta-analysis for the reasons outlined in Fig. 1. Agreement between the two reviewers at the second step of screening was almost perfect (estimated kappa $=0.93)$. Thereafter, two systematic and meta-analysis studies (Chambers et al. 2007, Vermeulen et al. 2007) on sliver dressing for chronic wound were reviewed and principle investigators contacted by e-mail to request additional information on meta-analysis. However, data were not available. Therefore, the final sample consisted of eight RCT studies published in English between 2004-2007. Of the eight studies, seven were published journal articles and one was unpublished conference article. All eight papers scored between 20-28 on the critical appraisal tool.

\section{Assessment of methodological quality}

Of the eight included studies, four were of high methodological quality. Two trials showed no evidence of sample size estimation (Romanelli \& Price 2005, Munter et al. 2006) and an intention-to-treat analysis (Romanelli \& Price 2005, Sigal-Grinberg et al. 2007). Four of the studies reported drop-out rates that varied from $10 \cdot 0-19 \cdot 2 \%$ and the remaining trials did not mention drop-out rates (Russell 2005, Jørgensen et al. 2006, Munter et al. 2006, Sigal-Grinberg et al. 2007). The sum of drop-outs from the group I was 25 and from the group C 24 . There was no significant difference found in any of the studies (Table 3).

\section{Study characteristics}

Of the 1399 combined patients in the eight RCT, 721 were allocated for silver-relating dressings (group I) and 668 for without silver dressings (group C). Five studies were from single countries: UK (2), France (2), Spain (1) and multiple countries (UK, Germany, Canada, USA, Demark, Italy, Netherlands, Belgium, Switzerland, Brazil and Slovenia). Exactly, 597 participants in the studies were females and 466 were males. There were also 336 patients whose gender was not given. Average age ranged from 58.9-74.9 years. Two trials
(Romanelli \& Price 2005, Sigal-Grinberg et al. 2007) did not give details of patient ages. In addition, $48.73 \%(n=579)$ of the studies reported including subjects with venous leg ulcer, 9.93\% $(n=118)$ with mixed venous/arterial ulcer, $16 \cdot 83 \%$ $(n=200)$ with pressure ulcer, $15 \cdot 40 \%(n=183)$ with diabetic foot ulcer and $9.09 \%$ with another type of non-healing chronic wound. Two trials (Russell 2005, Jørgensen et al. 2006) did not give details of wound type (Table 3).

All the trials compared silver-releasing dressing with a nonsilver-releasing dressing (foam dressing, alginate dressing and hydro-polymer adhesive dressing). Silver dressings included hydrophilic polyurethane foam (Romanelli \& Price 2005, Russell 2005, Jørgensen et al. 2006, Munter et al. 2006), hydroalginate dressing (Meaume et al. 2005, Sigal-Grinberg et al. 2007), activated charcoal dressing (Verdu Soriano et al. 2004) and hydrofibre (Jude et al. 2007). The duration of intervention varied from four to eight weeks, all five studies included data after four weeks, one study six weeks and two studies included data after eight weeks of intervention. The majority of studies $(n=4)$ conducted a weekly evaluation of wound bed progresses. The studies used the following physiological outcome variables: wound area $(n=6)$, odour $(n=3)$, maceration $(n=3)$, exudates $(n=3)$, wound bed tissues composition $(n=2)$ and pain $(n=2)$.

\section{Pooled efficacy and safety}

\section{Physiological outcomes}

To examine the overall efficacy and safety of silver-relating dressings, six results were retrieved from eight studies (in some cases, more than one result was retrieved from a study).The results of our meta-analysis shows a significant effect of group I in wound area reduction compared with group $\mathrm{C}$ with the effect size $0.28 \quad\left(\mathrm{CI}_{95}: 0 \cdot 16-0 \cdot 39\right.$, $p<0.001 ; t$-test). Heterogeneity tests were obtained for six studies showing no significant difference between studies ( $p=0 \cdot 497$; chi-square test).

Wound odour was described in three trials, which presented a significant effect of group I in wound odour improvement compared with group $\mathrm{C}$ with the effect size $0 \cdot 38\left(\mathrm{CI}_{95}: 0 \cdot 24\right.$ $0.52, p<0.001 ; t$-test). There was no significant betweenstudy heterogeneity ( $p=0 \cdot 302$; chi-square test).

For wound exudate, three trials showed a significant effect of group I in the wound exudate level reduction compared with group $\mathrm{C}$ with the effect size $0.31\left(\mathrm{CI}_{95}: 0 \cdot 17-0 \cdot 44\right.$, $p<0.001 ; t$-test). There was no statistical heterogeneity ( $p=0 \cdot 126 ;$ chi-square test).

A reduction in wound pain was described in two trials, which displayed a significant effect of group I more than group $C$ with the effect size $0.33 \quad\left(\mathrm{CI}_{95}: 0 \cdot 18-0 \cdot 47\right.$, 
$p<0.001 ; t$-test). There was no significant between-study heterogeneity $(p=0.758$; chi-square test).

\section{Psychological and economic outcomes}

The results of our meta-analysis shows a significant effect of group I in the EQ-5D (Standardised instrument for use as a measure of health outcome) compared with group $\mathrm{C}$ with the effect size $0 \cdot 18\left(\mathrm{CI}_{95}: 0 \cdot 04-0 \cdot 33, p=0 \cdot 013\right.$; $t$-test $)$. Heterogeneity test was obtained for two studies that showed no significant difference between studies ( $p=0 \cdot 349$; chi-square test). For dressing wear time, two trials showed a significant effect of group I compared with group $\mathrm{C}$ with the effect size $0.33\left(\mathrm{CI}_{95}\right.$ : $0 \cdot 19-0 \cdot 48, \quad p=0 \cdot 028 ; t$-test $)$. There was no significant between-study heterogeneity ( $p=0.645$; chi-square test).

\section{Adverse events}

Four of the studies included information about adverse events. No severe adverse events were registered in any of the studies. Three trials did not mention adverse events (Romanelli \& Price 2005, Munter et al. 2006, Sigal-Grinberg et al. 2007). The deterioration of peri-ulcer skin and burning sensation were the main local adverse events reported (Table 3).

\section{Sensitivity testing}

Sensitivity testing was conducted in relation to the type of dressing used and:

- wound area reduction

- wound odour

- wound exudates

- reduction in wound pain

- quality of life.

In all cases there was no statistically significant heterogeneity.

\section{Publication bias}

We minimised the potential for publication bias by conducting a thorough literature search that included gray literature and contacting experts. We also generated funnel plots and Egger's tests for the primary outcome (reduction in wound area), which included six studies demonstrating symmetry indicating no publication bias. In addition, we used Egger's linear regression test to detect publication bias (Whitehead 2002). The intercept was $0 \cdot 72$, with $95 \%$ CI $(-2 \cdot 20,3 \cdot 64)-$ concurring with the visual inspection of the funnel plot.

\section{Limitations of the study}

This review has some limitations. First, the review was exclusively drawn from publications in English or Chinese.
This has the potential for affecting the results of a meta-analysis (NHS Centre of Reviews and Dissemination 2001). Second, variability in the type of dressings and patient groups might affect the efficacy and safety of silver-releasing dressings. However, our post-hoc subgroup analysis did not verify this effect. Another limitation of this review was the exclusion of non-healing wounds over four to six weeks duration, such as burns, traumatic or postoperative wounds. This decision was because of the different bio-mechanisms between the two wound types (Ayello \& Cuddigan 2004). Furthermore, this decision was also guided by the fact that non-healing chronic wounds are much more common and contribute to the greatest health issues, not only in terms of direct cost to healthcare services, but also in terms of pain, economic loss and impaired quality of life experience by patients. Finally, all included trials differed in several dimensions, including characteristics of the participants and wound type, inclusion and exclusion criteria, type of dressing product, evaluation of outcome and status with regard to industry funding. In addition, no studies included research questions or hypotheses, leading to a possibility of reporting bias. Some studies may have lacked the power to adequately detect beneficial outcome. All studies were conducted in western healthcare environments. It is unknown whether patients with non-healing chronic wound from other regions of the world would respond similarly to the same interventions. Finally, we found that all of the open label trials showed a significant positive outcome. It is possible that this type of research design could lead to the problem of higher estimation of silver dressing efficacy through 'Novelty' or 'Hawthorne' effects.

\section{Discussion}

This systematic review adds to one previous review of silverrelated dressings in chronic wounds by Vermeulen et al. (2007), which included three RCT assessing the effectiveness of silver in the treatment of contaminated and infected acute or chronic wounds. However, the authors highlighted that there was insufficient evidence to recommend the use of silver dressings for treatment of infected or contaminated chronic wounds. The results of this meta-analysis support the hypothesis that silver-dressings can improve wound bed composition in non-healing, chronically infected wounds. We found not only significant effectiveness of physical outcomes, reduction in wound area, reductions in malodour, decreases in wound exudates and wound pain, but also improvement in the participant's quality of life and prolonged dressing wear time. The variety of outcome measures included in the studies within this meta-analysis strengthens the evidence base for their use - providing evidence of not only physical improve- 
ments but of an impact upon psychological and economic indicators too. Moreover, as 1399 subjects were involved in this meta-analysis, the results obtained can be expected to have more clinical significance than individual studies alone.

\section{Relevance to clinical practice}

Although providing a clear addition to the evidence base for practice this review also demonstrates the need for further investigation. First, several well-designed RCT are needed to clear up the continued uncertainty about the therapeutic effects of different type of silver-relating dressing on nonhealing chronic wounds in various clinical settings and patient populations. Second, it is also important to describe the silver-relating dressing delivery mode, indications, contraindications, frequency and duration of treatment in future studies. Third, the application of the findings of this review is restricted to settings and patients similar to those in the primary studies. Most of the included studies did not mention trial setting and the majority were conducted in Europe, therefore, primary research is needed to examine the efficacy and safety of silver-relating dressings in healthcare circumstances in the East. Finally, although evidence of effectiveness is an appropriate standard from which to base reimbursement policies only two trials demonstrated a positive effect upon wear time, thus, further studies are need to evaluate the costeffectiveness of silver-releasing dressings to inform health policy within wound care practice.

\section{Conclusion}

In conclusion, this meta-analysis of RCT confirmed that silverreleasing dressings can improve wound bed composition, enhance quality of life and save medical cost. However, we found that majority of the participants were older than 60 years of age and had several advanced chronic diseases. Understanding the differences in silver dressing efficacy among different populations is important when selecting patients for this treatment. Notwithstanding, this meta-analysis showed that silver dressings were associated with few adverse events and the authors of the papers reviewed reported no significance differences for these between groups I and C. However, it may be the case that with industry-funded trials adverse events may be under-reported; therefore, an adverse events assessment should be conducted when practitioners use this intervention.

\section{Acknowledgements}

This review was undertaken through the School of Health and Related Research and School of Nursing and Midwifery,
University of Sheffield. Andrew Booth is thanked for his comments on the manuscript.

\section{Contributions}

Study conception and design: SL, LC; data collection and analysis: SL, WH, YC and drafting and critical revision of manuscript: SL, MH, WH, LC.

\section{References}

Abrams KR \& Jones DR (2001) An illustrated guide to the methods of meta-analysis. Journal of Evaluation in Clinical Practice 7, 135-148.

Ayello EA \& Cuddigan JE (2004) Conquer chronic wounds with wound bed preparation. Nurse Practitioner 29, 8-27.

Bergin SM \& Wraight P (2006) Silver based wound dressings and topical agents for treating diabetic foot ulcers. Cochrane Database Systematic Reviews 1, CD005082.

Bolton L (2006) Are silver products safe and effective for chronic wound management? Journal of Wound, Ostomy and Continence Nursing 33, 469-477.

Bowler P (2003) Progression toward healing: wound infection and the role of an advanced silver-containing Hydrofiber ${ }^{\circledR}$ dressing. Ostomy/Wound Management 49, 2-5.

Chambers H, Dumville J \& Cullum N (2007) Silver treatment for leg ulcer: a systematic review. Wound Repair and Regeneration 15, $165-173$.

Fletcher J (2005) Wound bed preparation and the TIME principles. Nursing Standard 20, 57-65.

Giulio LT \& Barrett S (2005) The management of wounds using silvercel hydroalginate. Wounds UK 1, 70-77.

Gray D, Cooper P \& Timmons J (2006) Essential Wound Management: An Introduction for Undergraduates. Cromwell Press, Wiltshire.

Joergensen B, Gottrup F, Karlsmark T, Sibbald RG \& Bech-Thomsen N (2007) Ibuprofen Foam and Silver Wound Contact Layer: A Safe Combination for Treatment of Painful Critically Colonized Leg Ulcers. Proceedings of the 17th Conference of the European Wound Management Association, abstract 158.

Jørgensen B, Bech-Thomsen N, Grenov B \& Gottrup F (2006) Effect of a new silver dressing on chronic venous leg ulcers with signs of critical colonisation. Journal of Wound Care 15, 97-100.

Jude EB, Apelqvist J, Spraul M \& Martini J (2007) Prospective randomized controlled study of Hydrofiber ${ }^{\circledR}$ dressing containing ionic silver or calcium alginate dressings in non-ischaemic diabetic foot ulcers. Diabetic Medicine 24, 280-288.

Karlsmark T, Agerslev R, Bendz S, Larsen J, Roed-Petersen J \& Andersen K (2003) Clinical performance of a new silver dressing, Contreet Foam, for chronic exuding venous leg ulcers. Journal of Wound Care 12, 351-354.

Lazareth I, Ourabah Z, Senet P, Cartier H, Sauvadet A \& Bohbot S (2007) Evaluation of new silver foam dressing in patients with critically colonized venous leg ulcer. Journal of Wound Care 16, 129-132.

Leandro G (2005) Meta-Analysis in Medical Research. Blackwell, Oxford. 
Meaume S, Vallet D, Morere M \& Teot L (2005) Evaluation of a silver-releasing hydroalginate dressing in chronic wounds with signs of local infection. Journal of Wound Care 14, 411-419.

Melnyk BM \& Fineout-Overholt E (2005) Evidence-Based Practice in Nursing \& Healthcare: A Guide to Best Practice. Lippincott Williams \& Wilkins, London.

Moffatt CJ (2004) Wound bed preparation in practice. Available at: http://www.ewma.org/english/english.htm (accessed 20 March 2007).

Munter K, Beele H, Russell L, Crespi A, Grochenig E, Basse P, Alikadic N, Fraulin F, Dahl C \& Jemma AP (2006) Effect of a sustained silver-releasing dressing on ulcers with delayed healing: the CONTOP study. Journal of Wound Care 15, 199-206.

NHS Centre for Reviews and Dissemination (2001) Undertaking Systematic Review of Research on Effectiveness, 2nd edn. CRD Report Number 4, University of York, York.

O'Meara SM, Cullum NA, Majid M \& Sheldon TA (2001) Systematic review of antimicrobial agents used for chronic wounds. British Journal of Surgery 88, 4-21.

Ovington LG (2004) The truth about silver. Ostomy Wound Management 50, S1-S15.

Petticrew M \& Roberts H (2006) Systematic Reviews in the Social Sciences: A Practical Guide. Blackwell, Oxford.

Rayman G, Rayman A, Baker N, Jurgeviciene N, Dargis V, Sulcaite R, Pantelejeva O, Harding KG, Price P, Lohmann M, Thomsen JK, Gad P \& Gottrup F (2005) Sustained silver-releasing dressing in the treatment of diabetic foot ulcers. British Journal of Nursing 14, 109-114.

Rogers R \& Alvarez M (2004) Effect of a Silver Ion-Containing Wound Dressing on the Bacterial Burden of Chronic Venous Ulcers Presented at the 13th Annual Symposium on Advanced Wound.

Romanelli M \& Price P (2005) Health-related quality of life aspects after treatment with a foam dressing and a silver-containing foam dressing in chronic leg ulcers. Journal of the American Academy of Dermatology 52, 21.

Rucigaj TP (2007) Comparative Effects of Honey Based and Silver/ Charcoal Based Dressing on the Healing of Venous Leg Ulcers: A Randomized Clinical Study. Proceedings of the 17th Conference of the European Wound Management Association, abstract 78.

Russell L (2005) The CONTOP multinational study: preliminary data from the UK arm. Wounds UK 1, 44-54.

Schultz GS, Sibbald RG \& Falanga V (2003) Wound bed preparation: a systematic approach to wound management. Wound Repair and Regeneration 11, S1-S28.

Schuman H, Apelqvist J, Schmidtchen A \& Hansson C (2007) Open, Non-Comparative, Multicentre Investigation Exploring the Tolerance of an Absorbent Dressing Containing Silver Used in Chronic Wounds. Proceedings of the 17th Conference of the European Wound Management Association, abstract 120.
Serra N, Torres OG, Romo MI, Llovera JM, Vigil-Escalela CJ, Sotto MA \& González-Parra S (2005) Hydro-colloidal dressings which release hydro-active silver (Spanish). Revista de Enfermeria 28, 1318.

Sibbald R, Browne A, Coutts P \& Queen D (2001) Screening evaluation of an ionized nanocrystalline silver dressing in chronic wound care. Ostomy/Wound Management 47, 38-43.

Sibbald RG, Meaume S, Kirsner RS \& Munter KC (2005) Review of the Clinical RCT Evidence and Cost-Effectiveness Data of a Sustained-Release Silver Foam Dressing in the Healing of Critically Colonized Wounds. Available at: http://www.worldwidewounds.com/2005/december/Sibbald/ Silver-Foam-Dressings-Colonised-Wounds.html (accessed 4 May 2007).

Sigal-Grinberg M, Senet P, Lazareth I, Sauvadet A \& Bohbot S (2007) Evaluation of a New Contact Layer Impregnated with Silver Salts in the Management of Critically Colonized Venous Leg Ulcers. Result of a Randomized Clinical Trial. Proceedings of the 17th Conference of the European Wound Management Association, abstract 32 .

Sutton A, Abrams KR \& Jones DR (2001) An illustrated guide to the methods of meta-analysis. Journal of Evaluation in Clinical Practice 7, 135-148.

Tomaselli N (2006) The role of topic silver preparations in wound healing. The Wound, Ostomy and Continence Nurse Society 33, 367-380.

Vanscheidt W, Lazareth I \& Routkovsky-Norval C (2003) Safety evaluation of a new ionic silver dressing in the management of chronic ulcers. Wounds 15, 371-378.

Verdu Soriano J, Rueda LJ, Arboix PM, Munoz BA \& Lopez CP (2004) Effect of an Antimicrobial Wound Dressing with Silver in a Charcoal Mesh on Reduction of Bacterial Load in Chronic Wounds. Paper presented at the 2nd World Union of Wound Healing Societies' Meeting, Paris.

Verdu J, Gago M, Garcia F, Gaztelu V \& Lopez P (2007) Comparative Effectiveness between Three Silver Release Dressing on Chronic Infected Wounds. Proceedings of the 17th Conference of the European Wound Management Association, abstract 73.

Vermeulen H, van Hattem JM, Storm-Versloot MN \& Ubbink DT (2007) Topical silver for treating infected wounds. Cochrane Database Systematic Reviews 1, CD00 5486.

White R \& Cutting K (2006) Exploring the effects of silver in wound management - what is optimal? Wounds 18, 307-314.

Whitehead A (2002) Meta-Analysis of Controlled Clinical Trials. John Wiley \& Sons, New York.

Ziegler K, Gorl R, Effing J, Ellermann J, Mappes M, Otten S, Kapp H, Zoellner P, Spaeth D \& Smola H (2006) Reduced cellular toxicity of a new silver-containing antimicrobial dressing and clinical performance in non-healing wounds. Skin Pharmacology and Physiology 19, 140-146. 